\title{
Small-lymphoid cells and myeloid antigen expression in a patient with IgG myeloma: A case report
}

\author{
PENGJUN JIANG ${ }^{*}$, WEN XIA ${ }^{*}$, XUEMEI SUN, XINGBIN DAI and LIN LI \\ Department of Hematology, Affiliated Hospital of Nanjing University of Traditional Chinese Medicine, \\ Nanjing, Jiangsu 210029, P.R. China
}

Received March 2, 2015; Accepted December 18, 2015

DOI: $10.3892 / \mathrm{ol} .2016 .4197$

\begin{abstract}
Multiple myeloma is defined as a malignant proliferation of a single clone of plasma cells resulting in monoclonal immunoglobulin production. Due to the number of plasma cell morphological variants, difficulty is often faced during morphological diagnosis. The current study describes the case of a 49-year-old woman presenting with atypical plasma cell morphology detected by a bone marrow examination. Flow cytometric immunophenotyping determined the nature of the neoplastic cells as monoclonal myeloma cells with myeloid antigen expression. Serum electrophoresis with immunofixation and subsequent clinical findings confirmed this diagnosis. Therefore, the immunophenotyping of plasma cells in myelomas may be useful for the diagnosis of cases with atypical plasma cell morphology.
\end{abstract}

\section{Introduction}

Multiple myeloma (MM) accounts for $\sim 1 \%$ of all tumors and $13 \%$ of hematological malignancy cases (1). The median age of patients at myeloma diagnosis is 66 years, with diagnosis being particularly rare in individuals $<40$ years of age (1). The diagnosis of normal MM is commonly determined through a combination of clinical, pathological and radiological techniques and the subsequent findings (2). MM is often associated with extensive skeletal destruction, anemia, hypercalcemia, infections and renal failure (2). However, certain cases presenting with atypical features may be challenging for hematopathologists to diagnose (3). The current study describes a case of immunoglobulin G (IgG) myeloma presenting with small lymphoid cells. Diagnosis of the case based on morphology alone proved to be challenging, with

Correspondence to: Miss. Xuemei Sun, Department of Hematology, Affiliated Hospital of Nanjing University of Traditional Chinese Medicine, 155 Hanzhong Road, Nanjing, Jiangsu 210029, P.R. China E-mail: wokibb@gmail.com

*Contributed equally

Key words: immunoglobulin G, myeloma, small lymphoid, myeloid antigen flow cytometric immunophenotyping confirming the cells as monoclonal myeloma cells with myeloid antigen expression. The patient obtained complete remission following combination chemotherapy and received thalidomide as maintenance therapy. Several months later, the patient suffered a relapse and eventually succumbed to the disease.

\section{Case report}

In May 2012, a 49-year-female was admitted to the Department of Hematology, Affiliated Hospital of Nanjing University of Traditional Chinese Medicine (Nanjing, China), presenting with dizziness, episodic tiredness and a lack of motivation. Physical examination was unremarkable, with the exception of a cough, chest tightness and pallor. The hemoglobin and red blood cell counts were $72 \mathrm{~g} / 1$ (normal range, 110-150 g/l) and $2.34 \times 10^{12}$ cells $/ 1$ (normal range, $3.5 \times 10^{12}-5.0 \times 10^{12}$ cells $/ 1$ ) respectively, whilst the white blood cell and platelet counts were within normal ranges. Immunology tests indicated that the IgG $\kappa$ paraprotein and $\beta$-2-microglobulin levels were $66 \mathrm{~g} / 1$ (normal range, 6.94-16.20 g/l) and 3,879 $\mu \mathrm{g} / \mathrm{l}$ (normal range, 1,035-1,945 $\mu \mathrm{g} / \mathrm{l})$, respectively. Additionally, on serum free light chain evaluation, the $\kappa$ light chain concentration measured 7,960 $\mathrm{mg} / 1$ (normal range, 629-1,350 $\mathrm{mg} / \mathrm{dl}$ ) and the $\lambda$ light chain level measured $30 \mathrm{mg} / \mathrm{l}$ (normal range, 313-723 mg/dl), with a $\kappa / \lambda$ light chain ratio of 265.33 . Osteoporosis was revealed by computed tomography and X-ray examination.

A bone marrow aspiration was performed and the sample underwent cytological study. Small lymphoid or lymphoplasmacytic-like plasma cells were observed, and accounted for $22.5 \%$ of all nucleated cells in the bone marrow. The cells had round nuclei of a uniform size, the chromatin was dense and coarse, and the cytoplasm was slightly basophilic and scanty, wrapping closely around the nucleus (Fig. 1). The antibody expression in the cells was measured using a multiparameter flow cytometer (FC500 Flow Cytometer; Beckman Coulter, Inc., Brea, CA, USA). The results demonstrated that the cells (Fig. 2A) expressed cluster of differentiation (CD)38 (Fig. 2B) and CD33 (Fig. 2C). There was also $\kappa$ light chain restriction $(\kappa / \lambda=13.1)$ (Fig. 2D, E and F). The majority of the $\mathrm{CD} 138^{+}$myeloma cells expressed CD19, but lacked CD56 expression (Fig. 2G and H). The abnormal cells were negative for CD117, CD10, CD20, CD22, CD34 and CD13 expression (data not presented). Interphase fluorescence in situ hybridization (FISH) analysis 


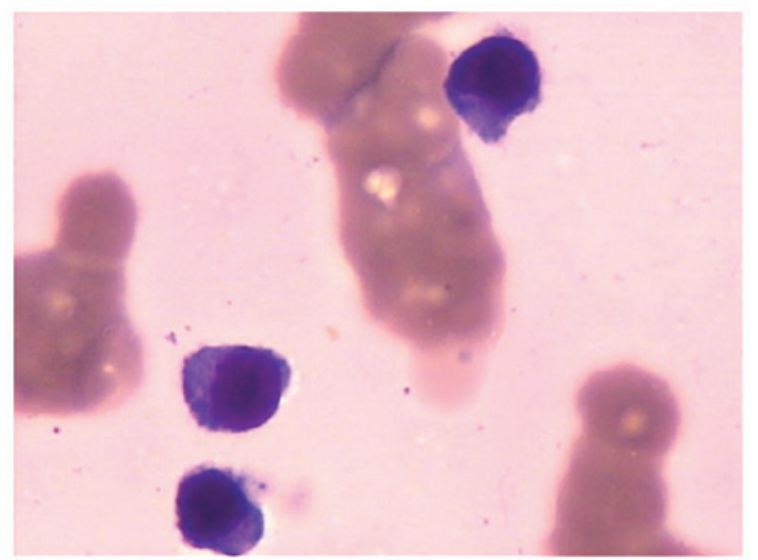

Figure 1. Bone marrow aspirate showing atypical plasma cells with round nuclei of uniform size and dense, coarse chromatin. The cytoplasm was scanty and slightly basophilic. Staining, Wright-Giemsa; magnification, $\mathrm{x} 1,000$.

on the bone marrow aspirate smear, using a probe specific for cyclin D1 (CCNDI)/IgH, did not demonstrate a fusion signal, and chromosome analysis revealed a normal karyotype (data not presented). According to the aforementioned findings, the patient of the present case was diagnosed with $\mathrm{IgG}$ myeloma. Subsequently, the patient was treated with a vincristine-doxorubicin-dexamethasone regimen that consisted of $1 \mathrm{mg}$ vincristine (days 1-4), $10 \mathrm{mg}$ doxorubicin (days 1-4) and $20 \mathrm{mg}$ dexamethasone (days 1-4, 9-12 and 17-20 for the first cycle and on days 1-4 for the next three cycles). Thalidomide (75 mg per night) was administered as maintenance therapy during each cycle of chemotherapy. The general conditions of the patient improved following the treatment. The lab tests revealed the following results: Bone marrow, $2.5 \%$ plasma cells (normal range, $0-2.0 \%$ ); red blood cells, $3.12 \times 10^{12}$ cells $/ 1$ (normal range, $3.5 \times 10^{12}-5.0 \times 10^{12}$ cells/l); hemoglobin, $101 \mathrm{~g} / 1$ (normal range, $110-150 \mathrm{~g} / \mathrm{l}$ ); $\mathrm{IgG} \kappa$ paraprotein, $15.8 \mathrm{~g} / \mathrm{l}$ (normal range, 6.94-16.20 g/l), $\beta$-2-microglobulin, 2,373 $\mu \mathrm{g} / 1$ (normal range, 1,035-1,945 $\mu \mathrm{g} / \mathrm{l}$ ); $\kappa$ light chain, 1,580 mg/dl (normal range, $629-1,350 \mathrm{mg} / \mathrm{dl}$ ); $\lambda$ light chain, $331 \mathrm{mg} / \mathrm{dl}$ (normal range, $313-723 \mathrm{mg} / \mathrm{dl}$ ); and $\kappa / \lambda$ ratio, 4.77 . Subsequently, consolidate therapy was discontinued by the patient. In May 2013, the patient was admitted to the Department of Hematology, Affiliated Hospital of Nanjing University of Traditional Chinese Medicine complaining of serious bone pain following an injury. The lab tests revealed the following results: white blood cells, $2.4 \times 10^{9}$ cells/1; hemoglobin, $105 \mathrm{~g} / 1$; blood urea nitrogen , $5.19 \mathrm{mmol} / 1$ (normal range, 1.70-8.30 $\mathrm{mmol} / \mathrm{l}$ ); creatinine, $47.2 \mu \mathrm{mol} / 1$ (normal range, 44-110 $\mathrm{mmol} / \mathrm{l}$ ); $\beta$-2-microglobulin, 3,518 $\mu \mathrm{g} / \mathrm{l}$; IgG, $70.7 \mathrm{~g} / \mathrm{l}$; and bone marrow, $18.5 \%$ plasma cells. The patient was treated with the DECP regimen, which consisted of $20 \mathrm{mg}$ dexamethasone, $100 \mathrm{mg}$ etoposide, $0.6 \mathrm{~g}$ cyclophosphamide and $30 \mathrm{mg}$ cisplatinum for 4 days. However, the patient succumbed 18 days later without remission.

\section{Discussion}

Diagnosis of typical MM is not often difficult. However, in a small number of cases, unusual morphological variants may
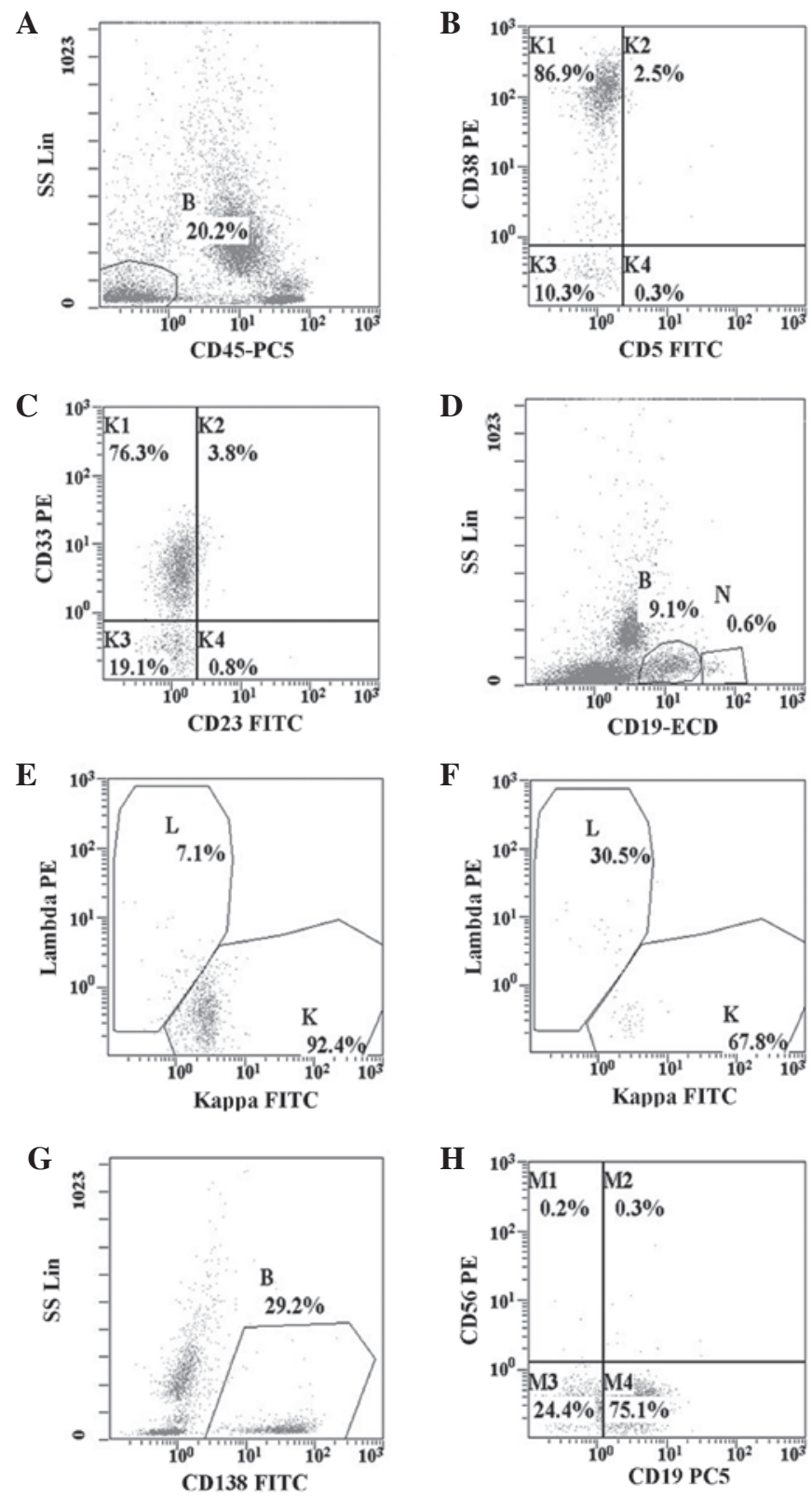

Figure 2. Flow cytometry dot plots presenting the cells of interest in (A) gate B (abnormal cells 20.2\%) on CD45/SS dot plot, with low SS and negative CD45 expression; ( $\mathrm{B}$ and $\mathrm{C}$ ) potent expression of CD38 and expression of CD33; (D-F) restricted expression of $\kappa$ light chain (cells of gate $\mathrm{N}$ were normal B cells); ( $\mathrm{G}$ and $\mathrm{H}$ ) expression of CD138 and CD19, with CD56-negativity. CD, cluster of differentiation; SS, side scatter; Lin, linear scale; PE, phycoerythrin; PC5, phycoerythrin cyanin 5; FITC, fluorescein isothiocyanate; ECD, electron-coupled dye.

pose a challenge when determining a morphological diagnosis, particularly in plasma cell leukemia $(2,3)$. In the current case, the neoplastic cells presented with round nuclei and dense, coarse chromatin. The cytoplasm was slightly basophilic and scanty, wrapping closely around the nucleus. All of the aforementioned features were similar to those of neoplastic cells, in particular small lymphoid or lymphoplasmacytic cells. The utilization of flow cytometry demonstrated that the cells had a low side scatter and were CD45- The cells were also CD138 ${ }^{+}, \mathrm{CD} 38^{+}$, $\mathrm{CD} 9^{+}, \mathrm{CD} 3^{+}$and CD56-. Plasma cell myelomas generally lack surface Ig, but express monotypic Ig (4). Like normal plasma cells, plasma cell myelomas also commonly express CD138, 
$\mathrm{CD} 79 \alpha$ and potent CD38; however, in contrast to normal plasma cells, they are frequently CD19- (5). Additionally, CD56 is abnormally expressed in $67-79 \%$ of cases $(6,7)$.

In patients with myeloma, it has been observed that disease aggression correlates with the absence of CD56; CD56- patients were found to exhibit higher levels of $\beta$-2-microglobulin, alongside a higher incidence of Bence Jones protein, extramedullary disease, thrombocytopenia and renal insufficiency when compared with CD56 $6^{+}$patients $(7,8)$. In addition to CD56, it has been reported that CD117 is expressed in the malignant plasma cells of certain patients with myeloma (4). Furthermore, Bataille et al (4) noted that a lack of CD117 was associated with aggressive disease and a significantly shorter survival time compared with $\mathrm{CD} 117^{+}$cases. Pozdnyakova et al (9) reported that the simultaneous assessment of CD56 and CD117 by flow cytometry identified cytogenetically distinct groups of plasma cell myeloma, and CCND1 rearrangement was almost exclusively observed in cases demonstrating CD117 and CD56 negativity.

CD33 is a glycoprotein expressed on myeloid cell surfaces and has a mass of $67-\mathrm{kDa}$. A small number of studies have observed the expression of CD33 on plasma cell surfaces; however, the reactivity of the marker has been noted in $6.5-12 \%$ of patients with myeloma $(10,11)$. The expression of CD33 in such patients is reported to be associated with certain clinical parameters; the $\mathrm{CD} 33^{+}$patient group had a lower survival rate compared to the $\mathrm{CD}^{-}$- patient group, thus indicating the clinicopathological significance of CD33 expression (12).

Certain cases of $\mathrm{CCND}^{+}$myeloma are associated with the $\mathrm{t}(11 ; 14)(\mathrm{q} 13 ; \mathrm{q} 32)$ rearrangement, involving the CCND1 gene (13). Such cases have been linked with a lymphoplasmacytic morphological appearance and may therefore be misdiagnosed, particularly if CCND1 and CD138 immunohistochemical staining has not been performed (13). However, in the present case, the FISH analysis for $C C N D$ I/IgH and the chromosome analysis appeared normal (data not presented). Due to the low frequency of aberrant antigen expression and the unclear association between morphology and myeloid antigenic expression, the possible prognostic indications of these features require further investigation.

In conclusion, forming a conclusive diagnosis for MM patients with unusual morphological appearances, based on morphology only, presents a challenge. In the present study, the flow cytometry technique allowed doctors to ascertain the nature of the neoplastic cells with atypical morphology. The present case possessed small-lymphoid cells and with myeloid antigen expression. Therefore, flow cytometry immunophenotyping may aid the diagnosis and the monitoring of minimal residual disease, particularly for patients that demonstrate no cytogenetical evidence.

\section{References}

1. Palumbo A and Anderson K: Multiple myeloma. N Engl J Med 64: 1046-1060, 2011

2. Lorsbach RB, Hsi ED, Dogan A and Fend F: Plasma cell myeloma and related neoplasms. Am J Clin Pathol 136: 168-182, 2011.

3. Heerema-McKenney A, Waldron J, Hughes S, Zhan F, Sawyer J, Barlogie B and Shaughnessy JD Jr: Clinical, immunophenotypic, and genetic characterization of small lymphocyte-like plasma cell myeloma: A potential mimic of mature B-cell lymphoma. Am J Clin Pathol 133: 265-270, 2010.

4. Bataille R, Jégo G, Robillard N, Barillé-Nion S, Harousseau JL, Moreau P, Amiot M and Pellat-Deceunynck C: The phenotype of normal, reactive and malignant plasma cells. Identification of 'many and multiple myelomas' and of new targets for myeloma therapy. Haematologica 91: 1234-1240, 2006.

5. Lin P, Owens R, Tricot G and Wilson CS: Flow cytometric immunophenotypic analysis of 306 cases of multiple myeloma. Am J Clin Pathol 121: 482-488, 2004.

6. Pellat-Deceunynck C, Barillé S, Jego G, Puthier D, Robillard N, Pineau D, Rapp MJ, Harousseau JL, Amiot M and Bataille R: The absence of CD56 (NCAM) on malignant plasma cells is a hallmark of plasma cell leukemia and of a special subset of multiple myeloma. Leukemia 12: 1977-1982, 1998.

7. Sahara N, Takeshita A, Shigeno K, Fujisawa S, Takeshita K, Naito $\mathrm{K}$, Ihara $\mathrm{M}$, Ono $\mathrm{T}$, Tamashima $\mathrm{S}$, Nara $\mathrm{K}$, et al: Clinicopathological and prognostic characteristics of CD56-negative multiple myeloma. $\mathrm{Br} \mathrm{J}$ Haematol 117: 882-885, 2002.

8. Sahara N and Takeshita A: Prognostic significance of surface markers expressed in multiple myeloma: CD56 and other antigens. Leuk Lymphoma 45: 61-65, 2004.

9. Pozdnyakova O, Morgan EA, Li B, Shahsafaei A and Dorfman DM: Patterns of expression of CD56 and CD117 on neoplastic plasma cells and association with genetically distinct subtypes of plasma cell myeloma. Leuk Lymphoma 53: 1905-1910, 2012.

10. Almeida J, Orfao A, Ocqueteau M, Mateo G, Corral M, Caballero MD, Blade J, Moro MJ, Hernandez J and San Miguel JF: High-sensitive immunophenotyping and DNA ploidy studies for the investigation of minimal residual disease in multiple myeloma. Br J Haematol 107: 121-131, 1999.

11. Robillard N, Wuillème S, Lodé L, Magrangeas F, Minvielle S, Avet-Loiseau H: CD33 is expressed on plasma cells of a significant number of myeloma patients, and may represent a therapeutic target. Leukemia 19: 2021-2022, 2005.

12. Sahara N, Ohnishi K, Ono T, Sugimoto Y, Kobayashi M, Takeshita K, Shigeno K, Nakamura S, Naito K, Tamashima S, et al: Clinicopathological and prognostic characteristics of CD33-positive multiple myeloma. Eur J Haematol 77: 14-18, 2006.

13. Rajkumar SV: Multiple myeloma: 2013 update on diagnosis, risk-stratification, and management. Am J Hematol 88: 226-235, 2013. 